Volume: 3, Issue: 2, May 2018, Pages: 263-267, DOI: http://dx.doi.org/10.19082/ah263

\title{
EVALUATION OF DEMOGRAPHIC CHARACTERISTICS AND FACTORS ASSOCIATED WITH POISONING IN CHILDREN ATTENDING THE KOODAKAN HOSPITAL OF BANDAR ABBAS
}

\author{
Reza Yazdani ${ }^{1}$, Abdolmajid Nazemi ${ }^{2}$, Ali Rashidi ${ }^{3}$, Aida Gholami ${ }^{3}$, Najmeh Rastikerdar ${ }^{4}$, Hamidreza Mahboobi $^{3}$ \\ 1: M.D. of Emergency Medicine, Assistant Professor, Trauma and Medical Emergencies Research Center, Faculty \\ of Medicine, Hormozgan University of Medical Sciences, Bandar Abbas, Iran \\ 2: M.D. of Pediatrics, Associate Professor, Department of Pediatrics, Faculty of Medicine, Hormozgan University of \\ Medical Sciences, Bandar Abbas, Iran \\ 3: M.D, Student Research Committee, Faculty of Medicine, Hormozgan University of Medical Sciences, Bandar \\ Abbas, Iran \\ 4: M.Sc. of Psychology, Behavioural and Neurosciences Research Center, Faculty of Medicine, Hormozgan \\ University of Medical Sciences, Bandar Abbas, Iran
}

\section{TYPE OF ARTICLE: ORIGINAL}

\begin{abstract}
Background: Poisoning is a major public health problem and is still one of the most common causes of hospitalization and treatment of patients in emergency wards. Poisoning in children is also one of the most important concerns of societies that mostly occurs incidental.

Objective: The goal of this study was to identify the demographic characteristics and factors associated with poisoning in children.

Methods: In this retrospective cross-sectional descriptive-analytic study, all files on patients diagnosed with poisoning, and hospitalized from the start of 2006 to the end of 2011 were reviewed. The required data were extracted from the collected information according to the designed checklists (which were extracted confidentially and without the use of their names or family name after approval from Hormozgan University of Medical Sciences), and were used to complete them. Each checklist was specified with its own special code. Finally, IBM SPSS statistics software 22, descriptive statistical tests (means, standard deviations, frequencies), and analytic statistical tests such as Chi-square and independent samples T-test were used to analyze the data.

Results: The hospitalized children consisted of $272(44.6 \%)$ girls and $338(55.4 \%)$ boys with the average age of $37.7 \pm 30.05$ months. In $517(85.6 \%)$ of the cases, poisoning was accidental, $95.2 \%$ of the patients (577 cases) had no history of poisoning, and $84.8 \%$ (518 patients) had never been outpatients before their hospitalization nor had they received any healthcare. The average interval between occurrence of poisoning and transfer to hospital was $4.76 \pm 4.36$ hours. The most common clinical symptom in these patients $(57.1 \%)$ was low level of consciousness, the mean length of hospitalization was $2.09 \pm 1.32$ days, and there were $7(1.1 \%)$ cases of death. The most common cause of poisoning $(54.1 \%)$ was drugs, and the majority of poisoning cases $(29.7 \%)$ happened in autumn. There were no differences between the genders except in the number of poisoning cases in various seasons $(\mathrm{p}=0.02)$.

Conclusion: Poisoning is one of the common causes of children going to the Children's Hospital in Bandar Abbas and being hospitalized there. Considering the high number of accidental poisoning cases, the need for greater knowledge of parents regarding prevention of poisoning is increasingly felt.

KEYWORDS: Poisoning, Children, Demographic factors
\end{abstract}

\section{INTRODUCTION}

Poisoning is a major public health problem and is still one of the most common causes of hospitalization and treatment of patients in emergency wards $(1,2)$. In general, $7 \%$ of people visiting emergency wards are patients who have been affected by poisoning in various ways (1). Poisoning in children is also one of the main concerns of societies (3). Every year, more than 2 million people are poisoned in the United States, 50\% of whom are children under 5 years of age or younger, with the least prevalence in children in the 6-12 year-old age group (4). However, in one study, it was found more than $5 \%$ of the total cases of poisoning were in children less than 5 years old (5)

\section{Correspondence:}

Aida Gholami, Tel: +98.9179161208, Email: aida.gholami1368@gmail.com

Received: Decemebr 30, 2016, Accepted: February 14, 2018, Published: May 2018

iThenticate screening: November 03, 2017, English editing: February 14, 2018, Quality control: March 25,2018

(C) 2018 The Authors. This is an open access article under the terms of the Creative Commons Attribution-NonCommercialNoDerivs License, which permits use and distribution in any medium, provided the original work is properly cited, the use is non-commercial and no modifications or adaptations are made. 
while, in another, this figure was reported to be up to $80 \%$ (6). Poisoning in children is accidental in most cases and results from their curiosity, or happens because drugs and poisons are improperly stored in homes (3). Poisoning is very prevalent in developed countries and is on the rise in developing ones, so that 8.2 million people are poisoned in the United States every year, 1.6 million of whom are children mostly under 6 years of age (5). However, a study conducted in New Zealand found that poisoning was of low prevalence, and rarely happened in that country (7). Rate of fatality in children resulting from poisoning is very low, and it was found to be $0.2 \%$ in one study (8) and 3 $5 \%$ in others (5). Various drugs, hydrocarbons such as kerosene, bleach, pesticides, insecticides, and cosmetics are the most frequent causes of poisoning in children, and more than $76 \%$ of these cases happen due to ingesting these materials (9). Among drugs, benzodiazepines and analgesics most frequently cause poisoning in children (7, 8, 1013). Other studies have pointed also to poisoning resulting from domestic materials such as detergents and bleach (7), metals and snake poison (8), poisonous strawberries (7), and kerosene, pesticides, and narcotics (14). In another study, factors causing poisoning were classified according to age. It was found that medical treatment of children in their first year of life by their parents, ingesting detergents by 2-3 year-old children, accidental swallowing of drugs found in homes by 3-5 year-old children, and taking drugs for committing suicide by schoolchildren and adults, were the most prevalent causes of poisoning (6). Digestive, neurological, cutaneous, and respiratory complications are the main complications observed in poisoning (7), pupil contraction happens in $31.9 \%$ cases, while $13.9 \%$ of poisoned patients have abnormal electrocardiograms (ECGs) (14). In one article, the case report suggested poisoning of a 30-month old child by methadone with lowered level of consciousness, generalized tonic-clonic seizures followed by cerebral edema (15). This research studied the demographic characteristics of, and factors related to poisoning in children hospitalized in the Children's Hospital in Bandar Abbas.

\section{MATERIALS AND METHODS}

In this retrospective cross-sectional descriptive-analytic study, all files of patients diagnosed with poisoning, and hospitalized from the start of 2006 to the end of 2011 (a total of 612 records in a six-year period) were reviewed with the help of the Medical Record Department of the children's Hospital in Bandar Abbas. Food poisoning and poisoning caused by bites were not included in the study, neither were records with incomplete information. The records were selected based on their record numbers and the codes given to them in the medical record system for patients hospitalized with poisoning. Information concerning the patients including age, gender, agents causing poisoning, season and time of going to the hospital, and medical care received before being referred to the hospital, was collected from the records. Also included was the nature of the poisoning (intentional or accidental), history of previous instances of poisoning, vital signs at admission, length of hospitalization, and health conditions of the patients at discharge from the hospital. The data specified in the designed checklists confidentially and without use of their names or family name after approval from Hormozgan University of Medical Sciences was extracted from the obtained information and the questionnaires (each specified with its own special code) were completed. Finally, SPSS 22 and descriptive statistical tests (means, standard deviations, and frequencies) and analytical statistical tests (such as chi-square and Independent-samples t-test) were used to analyze the extracted data.

\section{RESULTS}

Of the poisoned children who were hospitalized, $272(44.6 \%)$ were girls and $338(55.4 \%)$ boys. Their mean age was $37.7 \pm 30.05$ months, $517(65.6 \%)$ were accidentally poisoned, $21(3.47 \%)$ of the intentional cases were related to suicide attempts, $577(95.2 \%)$ of the patients had no history of poisoning, and $518(84.8 \%)$ of them had not been outpatients nor had they received medical care prior to their hospitalization. The average interval between poisoning and referral to the hospital was $4.76 \pm 4.36$ hours. At admission, patients were examined for vital signs, vomiting, and for changes in their levels of consciousness. Their mean body temperature and heart rate were $36.6 \pm 0.7$ and $108.3 \pm 22.9$, respectively. Decreased consciousness level was the most prevalent clinical sign in the patients who went to the hospital so that $347(57.1 \%)$ had lowered consciousness levels and $183(30.1 \%)$ complained of vomiting at admission. Of the patients who visited the hospital, 109 (17.9\%) were discharged after receiving initial medical care, and of the 498 hospitalized patients, $452(74.5 \%)$ were hospitalized in the ward and $46(7.6 \%)$ in the intensive care unit (ICU). At the end of the reviewed period, 307 patients $(50.6 \%)$ with generally satisfactory health conditions, and $293(48.3 \%)$ at their own requests, were discharged from the hospital. The mean length of hospitalization was $2.09 \pm 1.32$ days; and there were $7(1.1 \%)$ cases of deaths. The most common causes of poisoning were drugs (54.1\%) and opium and opioids (37.7\%), and the least frequent were hydrocarbons $(0.2 \%)$. The most prevalent drugs causing poisoning were benzodiazepines $(12.7 \%)$, antibiotics $(5.2 \%)$, and anti-seizure drugs (4.8\%). Autumn and winter with 29.7 and $20.4 \%$ were the seasons with the most and the least number of poisoning cases, respectively. Among the studied parameters regarding poisoned patients who went to the hospital, there were no 
differences between the genders except for the number of poisoning cases in the various seasons, which showed significant differences between the genders $(p=0.02)$.

\section{DISCUSSION}

In this research, poisoning was more common among boys than girls (55.4\% versus $44.6 \%)$, which agrees with two studies by Farnaghi et al. conducted in 2003 and 2007, in the first of which $68 \%$ of the patients were boys and in the second one, the ratio of boys to girls was 2 to $1(23,28)$. Talebian et al. (24), Ghorshi et al. (27), Vazirian et al. (26), Farzaneh et al. (16), and Haresabadi et al. (17) found 66.4, 53.3, 61, 58.6, and 58.8\% of the poisoned children were boys. Moreover, Besharat et al. (19) found there were 38 boys and 29 girls hospitalized for poisoning, and Izuora et al. (31) found similar results, while Zare Fazollahi reported that equal numbers of boys and girls were hospitalized for poisoning (20) and Sahin et al. observed 51.6\% of the children hospitalized for poisoning were girls (29). Incidence of poisoning being more common among boys than girls might be because of playfulness that is more among boys. The mean age of patients in this study was 37.7 \pm 30.05 months. However, Farzaneh et al. (16) found this mean to be 4.1 years (and the 1-4 year-old age group with $62.5 \%$ the most frequently poisoned). Farnaghi et al. (23) reported the average age of poisoned children was 4.3 \pm 3.5 , and Haresabadi et al. (17) observed the 6-month old age group with $28 \%$ had the highest number of poisoning cases. Zare Fazollahi et al. (20) found the highest number of poisoning cases (46\%) in children less than 5 years old, and Vazirian et al. (26) reported the 2-4 year-old age group with $36.7 \%$ had the largest number of poisoning cases. This range of age for poising (2-5 years) in most of the studies can be because of more curiosity of this age children to have new experience by eating new things that is common in this age. In this research, $85.6 \%$ of the poisoning cases happened accidentally, while Sahin et al. (29) and Yip et al. (30), in their studies on the less than 12-year-old age group reported 73.3 and $92 \%$ of the poisoning cases were accidental, respectively. Zare Fazollahi et al. (20), Hasanian Moghaddam et al. (22), Azin et al. (21), Vazirian et al. (26), Ghorshi et al. (27), and Farnaghi et al. (23) reported the percentages of accidental poisoning were $22.5,26,24,59.9,95$, and $100 \%$, respectively. The incidental poisoning can also be linked to the curiosity of this age children that without any understanding, eat poisons. In this study, reduced levels of consciousness with $57.1 \%$ was the most common clinical symptom, which was similar to results found by Vazirian et al (26) and Besharat et al. (19), with 36 and 30.3\%, respectively, and to prevalence of the sleepiness symptom found by Izuora et al. (31). Among other conducted studies, Farnaghi et al found the symptoms of not drinking a sufficient amount of milk and cyanosis the most common with 86 and 66\%, respectively, (24), while Talebian et al. (24) and Yip et al. (30) reported digestive symptoms with $68 \%$ were the most prevalent. This difference of the most common clinical symptom is related to the type of poison that has difference among the above studies. This research showed that the average length of hospitalization period was $2.09 \pm 1.32$ days, while Farzaneh et al. (16) reported it to be $1.7 \pm 0.2$ days. In this study, there were $7(1.1 \%)$ cases of death resulting from poisoning, while Farnaghi et al., in their two studies (28) and (23) found 2 and $37(0.33 \%)$ cases of death, respectively. Ghorshi et al. (27), Vazirian et al. (26), Hasanian Moghaddam and Pajoomand (25), Besharat et al. (19), Haresabadi et al. (17), and Yip et al. (30), observed $3(0.95 \%), 2(2.4 \%), 272(1 \%), 2.9 \%, 304(8.1 \%), 4,1$, and $3(0.3 \%)$ cases of death, respectively. The most common causes of poisoning in this study (conducted in Bandar Abbas) were drugs $(54.1 \%)$ and opium and opioids (37.7\%), and the least common, hydrocarbons (0.2\%). Haresabadi et al. in Bojnurd (17) and Farzaneh et al. in Ardabil (16) found narcotics and drugs to be the most prevalent causes of poisoning with $134(63.5 \%)$ and $60.71 \%$ of the cases, respectively. Hasanian Moghaddam and Pajoomand in Tehran (25) noticed drugs were the most common cause of poisoning in patients going to the hospitals, with antidepressants, benzodiazepines, and anti-seizure drugs topping the list. In the study conducted by Zare Fazollahi et al. in Orumiyeh, it was found that the most prevalent causes of poisoning were drugs $(49.9 \%)$, kerosene $(14.1 \%)$, food and plant materials $(11.7 \%)$, detergents $(8.1 \%)$, insect and snake-bites $(6.7 \%)$, pesticides $(6.1 \%)$, and narcotics $(3.4 \%)$. In the study conducted by Vazirian et al. in Kermanshah (26), it was found that drugs were the most common cause of poisoning (44.2\%). Ghorshi et al. in Tabriz (27) observed drugs, hydrocarbons, organophosphates, atropine and Datura products, rat poison, opiates, carbon monoxide and, finally, (alcohol, mushrooms, insect- and other animal bites, acids, and bases), caused 45.5, 0.26, 7, $6,3.6,2.9,2.2$, and $6.8 \%$ of poisoning cases, respectively. In research carried out by Talebian et al. in Kashan (24), drugs, kerosene, and food materials with 42, 31.1, and 10.9\% of the cases were the main causes of poisoning, respectively. Farnaghi et al. in Tehran (28) found opium and drugs (and poisons) caused 78 and 22\% of poisoning cases, respectively. In research conducted by Yip et al. in Hong Kong (30), it was observed that drugs (with analgesics, stimulants, and antihistamines ranking first to third) with $63 \%$ of the cases were the most common cause of poisoning, followed by domestic materials and alcohol. Sahin et al., in Turkey, found drugs with 48.3, swallowing acids and bases with 23.1 , and carbon monoxide with $12.5 \%$ were the most prevalent causes of poisoning. The most common drugs that caused poisoning were tricyclic antidepressants (11.7\%) followed by methylphenidate (29). In the study of Izuora et al., conducted in Saudi Arabia, it was observed that 108 cases 
$(64.3 \%)$ of poisoning were caused by drugs and $60(35.7 \%)$ by other domestic materials (31). Unfortunately, because of no control on over-the-counter (OTC) medications in Iran and also high prevalence of addiction, children have easier accessibility to the poisons that caused most prevalent poisoning among the above studies. Also, the least common rate of hydrocarbons can be because of Bandar Abbas' warm weather, and less requirement of hydrocarbons like oil or gasoline. As for seasonal prevalence, the season with the most cases of poisoning in this study was autumn (29.7\%), and the season with the least cases was winter with $20.4 \%$. However, Besharat et al. (19), Haresabadi e al. (17), Farzaneh et al. (16) Vazirian et al. (26) found summer to be the season with the most number of poisoning cases with $56(26.5 \%), 32.7 \%$, and $33.7 \%$ of the cases, respectively. Farnaghi et al. (23) also observed that summer had the highest percentage of poisoning cases.

\section{CONCLUSIONS}

Poisoning is one of the most common causes why children go to, and are hospitalized in the Children's Hospital in Bandar Abbas. There are no significant differences between the genders with respect to the studied parameters, except for the season with the highest percentage of poisoning cases. The most prevalent cause of poisoning are drugs and, therefore, it is increasingly felt that parents must be educated about storing drugs in homes so as to prevent accidental poisoning of children.

\section{ACKNOWLEDGMENTS:}

This research was Dr. Ali Rashidi and Dr. Aida Ghjolami's medical degree thesis. We gratefully appreciate Koodakan Hospital personnel for their excellent cooperation.

\section{CONFLICT OF INTEREST:}

The authors declare that they have no conflict of interests.

\section{FOUNDING:}

The authors received financial support from Research Deputy of Hormozgan University of Medical Sciences.

\section{AUTHORS' CONTRIBUTIONS:}

All authors contributed to this project and article equally. All authors read and approved the final manuscript.

\section{REFERENCES:}

1) Lamireau T, Llanas B, Kennedy A, Fayon M, Penouil F, Favarell-Garrigues JC, et al. Epidemiology of poisoning in children: a 7 -year survey in a paediatric emergency care unit. Eur J Emerg Med. 2002; 9(1): 914. doi: 10.1097/00063110-200203000-00004. PMID: 11989508.

2) Viccellio P. Emergency toxicology. Philadelphia: Lippincott-Raven. 1998: 4-8.

3) George C, Rodgers Jr, Nancy J. Matyunas poisoning. Epidemiology and approach to management in Nelson, Textbook of pediatrics, 17th ed: Saunders; 2004: 2362-63.

4) Behrman Richard. Poisoning in Nelson essential of pediatrics 18th edition. 2008: 339.

5) Hoffman RJ, Osterhoudt KC. Evaluation and management of pediatric poisoning. Pediatr Case Rev. 2002; 2: 51-63. doi: 10.1097/00132584-200201000-00007. PMID: 12865696.

6) Gauvin F, Bailey B, Bratton SL. Hospitalizations for pediatric intoxication in Washington state, 1987_1997. Arch Pediatr Adolesc Med. 2001; 155(10): 1105-10. doi: 10.1001/archpedi.155.10.1105. PMID: 11576004.

7) Yates KM. Accidental poisoning in New Zealand. Emerg Med J. 2003; 15(3): 244-9. doi: 10.1046/j.14422026.2003.00443.x. PMID: 12786646.

8) Kashef S, Harati H. Acute poisoning in pediatric age group. Journal of Shahid Sadoughi University of Medical Science Health Service. 2002; 1(2): 42-6.

9) Behrman Richard. Poisoning in Nelson essential of pediatrics 4th edition. 2002: 113.

10) Kooshanfar A. Etiology of under 12-year-old children poisoning in Loghman Hakim hospital, 1997. Pejouhandeh. 2002; 7(1): 71-4.

11) McCaig LF, Burt CW. Poisoning related visits to emergency department in the United States, 1993-1996. J Toxicol Clin Toxicol. 1999; 37(7): 817-26. doi: 10.1081/CLT-100102460. PMID: 10630264.

12) Agran PF, Anderson $C$, Winn $D$, Trent R, Walton Haynes L, Thyayer $S$, et al. Rates of pediatric injuries by 3 -months intervals for children 0 to 3 years of age. Pediatrics. 2003; 111(6 Pt 1): e683-92. PMID: 12777586. 
13) James LP, Abel K, Wilkinson J, Simpson PM, Nichols MH. Phenothiazin, Butyrophnone and other psychotropic medication poisoning in children and adolescents. J Toxicol Clin Toxicol. 2000; $38(6)$ : 615 23. doi: 10.1081/CLT-100102010. PMID: 11185968.

14) Motlagh ME, Nazari Z. Epidemiologic study of pediatric poisoning in Amir kabir and Abozar hospital of Ahvaz in the year 2000. Scientific journal of forensic medicine. 2002; 27(8): 39-42.

15) Fayyazi A, Khajeh A, Bagheri M, Ahmadi S. Acute Hydrocephaly Following Methadone Intoxication in a Child. Iranian Journal of Child Neurology. 2012; 6(1): 35-8.

16) Esmaeil F, Amani F, Mirzarahimi M, Nasrollahtabar M, Sayad Rezaei I. Epidemiological study of acute poisoning in children referred to Bu_Ali of Ardabil, 2007-2011. J Ardabil Univ Med Sci. 2014; 14(1): 5562.

17) Haresabadi M, Sedaghat M, Vejdani MA, Ahrari SH, Toghian Chaharsoughi N, Momeni AV. Epidemiologic study of acute poisoning in children aged under 12 years referred to Imam Reza hospital 2010-2012. Journal of North Khorasan University of medical science. 2013; 5(1): 47-53.

18) Zarif hoshiar J, Rostaminejad M, Aivazi AA. Evaluation of the clinical signs and para clinical findings between 2010 and 2011 referred to Loghman Hakim hospital outcomes of Amphetamins poisoning in children. Journal of Ilam University of medical sciences. 2013; 21(1): 123-8.

19) Besharat S, Besharat M, Akhavan Masouleh A, Jabari A, Yazdi HR. Opium intoxication in children under 5 years old, Golestan-Iran 2006-2007. Journal of Gorgan University of medical science. 2010; 12(1): 5985.

20) Zare Fazl Elahi Z, Maleki M. Epidemiology of poisoning in children admitted to Urmia Imam hospitalduring 2002-2006. Scientific journal of forensic medicine. 2009; 15(3): 171-5.

21) Azin SA, Shahidzadeh Mahani A, Abadi M, Omidvari S, Montazeri A. Substances involved in human poisoning a comparison between intentional and accidental poisoning cases. Iranian journal of epidemiology. 2008; 4(2): 7-17.

22) Hasanian Moghadam H, Pajoumand A. A one-year epidemiological study of acute poisoning among adults and adolescent admitted to Loghman hospital, Tehran between 2005 and 2006. Pejouhandeh. 2007; 12(3): 169-76.

23) Farnaghi F, Hassanian-Moghaddam H, Faghihi Langroodi T. Fatal poisoning and its related factors among children admitted to loghman hospital, 1995-2004. Pejouhandeh. 2009; 13(6): 529-35.

24) Talebian A, Doroodgar A, Salehi E, Akbari H. The Epidemiology of poisoning in inpatient children in Kaashan shaheed Beheshti Hospital during 1997-2002. Journal of Legal Med. 2003; 9(3): 122-6.

25) Hasanian Moghadam H, Pajoumand A, Sarjamei S. One year epidemiological study of acute adult and adolescent admitted to Loghman hospital, Tehran 2004-2005. Scientific journal of forensic medicine. 2008; 13(4): 235-40.

26) Vazirian SH, Mohammad Nejad M, Moghadasi AR. Epidemiological evaluation of poisoning in children hospitalized at Razi \& Shahid Fahmideh, Kermanshah, 2002-2003. The Scientific Quarterly. 2004; 8(2): 37-46.

27) Ghorshi ZA, Soltani-Ahari H. Acute poisoning in inpatient of children hospital of Tabriz. Research and scientific journal of Ardebil medical university sciences. 2003; 9(3): 59-63.

28) Farnaghi F, Mir zendedel S. Epidemiology of neonatal poisoning in Loghman Hakim hospital, 1996-2001. Pejouhandeh. 2003-2004; 8(5): 351-4.

29) Sahin S, Carman KB, Dinleyici EC. Acute Poisoning in Children; Data of a Pediatric Emergency Unit. Iran J Pediatr. 2011; 21(4): 479-84. PMID: 23056835, PMCID: PMC3446134.

30) Yip WL, Ng HW, Tse ML, Lau FL. An Epidemiological Study of Pediatric Poisoning in Hong Kong. Hong Kong J Paediatr. 2011; 16(1): 25-31.

31) Izuora GI, Adeoye A. A seven-year review of accidental poisoning in children at a military hospital in Hafr Al Batin, Saudi Arabia. Ann Saudi Med. 2001; 21(1-2): 13-5. doi: 10.5144/0256-4947.2001.13. PMID: 17264581 . 